\section{PARE0014 PATIENT VOICE IN GOUT - A EUROPEAN PATIENT SURVEY TO UNDERSTAND THE NEEDS OF PEOPLE LIVING WITH GOUT}

Ana Vieira ${ }^{1}$, Sebastian Micallef ${ }^{2}$, Mary Vella ${ }^{3}$, Brian Lynch $^{4}$, Neil Betteridge $^{5}$, Gudula Petersen ${ }^{6}$, Victoria Romero Pazos ${ }^{7} .{ }^{1}$ Liga Portuguesa Contra as Doenças Reumáticas, Lisboa, Portugal; ${ }^{2}$ AGORA, Athens, Greece; ${ }^{3}$ Arthritis and Rheumatism Organisation Malta, Mgarr, Malta; ${ }^{4}$ Arthritis Ireland, Dublin, Ireland; ${ }^{5}$ Neil Betteridge Associates, London, United Kingdom; ${ }^{6}$ Grünenthal, Aachen, Germany; ' Liga Reumatológica Española, Madrid, Spain

Background: Gout is one of the most common form of inflammatory arthritis in Europe, but awareness of it is relatively low. There is limited information available about the impact of gout on patients, and more generally on society.

Objectives: To give gout patients a voice to better understand the impact that the disease has on their lives.

Methods: From June to September 2018, gout patients from 14 European countries were invited to complete a 15 minutes online survey. Adult (18+) patients diagnosed with gout who met the criteria and finished the survey were included in the analysis. The design and content of the survey has been developed together with several patient and clinical experts to ensure that the most relevant aspects of the disease were covered. The questionnaire was translated into 11 different languages and checked that patient-friendly language was used. Patients were recruited via patient associations, leaflets provided to doctors and consumer online market research panels to reach the targeted number of patients.

Results: 1,100 gout patients completed the survey, $78 \%$ of respondents were male and $22 \%$ female. The mean age of participating patients was 55 years, $56 \%$ were employed or studying. The mean age of patients at diagnosis was 45 years and $38 \%$ were diagnosed during their first flare. The patients had on average 2.9 flares per year and the length of their last flare was 5 days on average. $84 \%$ of patients experienced moderate to severe pain with their most recent flare, $63 \%$ had severe pain with their worst flare ever. Patients reported that gout has a significant impact on their daily activities: on their ability to walk $(59 \%)$, changes in mood and mental well-being $(43 \%)$ and difficulties relating to their partner $(26 \%) .27 \%$ of patients reported that their selfesteem has dropped.

Inconvenience (53\% of patients), agony (37\%) and frustration (32\%) were the words patients most often associated with gout. $10 \%$ of patients (or a family member) have retired or lost a job because of their gout.

Despite reporting these not-insignificant impacts of gout on their lives, $79 \%$ of patients said that they are satisfied with their current treatment. However, two-thirds (68\%) of younger patients (18-35 years) reported that they are satisfied with their current treatment.

$69 \%$ of gout patients felt they have an open and trusted relationship with their doctor. But $42 \%$ of patients told their doctor about $<50 \%$ of their flares in the year. Over a quarter of gout patients who have had 5 or more flares feel they are wasting their doctor's time. $60 \%$ of patients said that they know nothing or very little about their condition, and $94 \%$ of the patients rated that there is no or very little knowledge amongst the general public about gout.

Conclusion: The results of this survey demonstrate that gout has a significant impact not only on patients, but also on their families and society. Gout seems to lead to stigma and many patients may feel guilty about their lifestyle choices. Actions need to be taken to manage dissatisfaction of patients and to encourage them to speak up to request better management of the disease. There seems to be an urgent need to educate both patients and the general public about the seriousness of gout and the burden on patients and their families. The results of this survey will be used for communication with healthcare professionals to better address patients' unmet needs.

Acknowledgement: The Survey was conducted by Hall \& Partners and funded by Grünenthal $\mathrm{GmbH}$.

Disclosure of Interests: Ana Vieira: None declared, Sebastian Micallef: None declared, Mary Vella: None declared, Brian Lynch: None declared, Neil Betteridge Consultant for: Amgen, Eli Lilly, Grunenthal, GSK, Heart Valve Voice, Janssen, Roche, Sanofi Genzyme and Sanofi Regeneron, Speakers bureau: Amgen, Eli Lilly, Grunenthal, GSK, Heart Valve Voice, Janssen, Roche, Sanofi Genzyme and Sanofi Regeneron, Gudula
Petersen Employee of: Grünenthal, Victoria Romero Pazos: None declared

DOI: 10.1136/annrheumdis-2019-eular.4879

\section{Psychosocial support}

\section{PARE0015 EMOTIONAL HEALTH AND WELL-BEING MATTERS}

Matthew Bezzant ${ }^{1}$, Hayley Mcbain ${ }^{2}$, Ailsa Bosworth ${ }^{1}{ }^{1}$ National Rheumatoid Arthritis Society, Maidenhead, United Kingdom; ${ }^{2}$ City, University of London, London, United Kingdom

Background: The most common co-morbidities amongst people with RA are mental health conditions, such as depression and anxiety, as evidenced by previous surveys and reports by the NRAS. NRAS also understands, through interaction with its membership across the UK, that mental health and well-being are important issues for people living with RA and JIA. NRAS therefore partnered with City University to undertake a survey exploring the impact of RA and adult JIA on mental health.

Objectives: To explore the psychological impact of Rheumatoid Arthritis (RA) and Juvenile Idiopathic Arthritis (JIA), along with any psychological support people may have received or would like to have access to, to help manage the anxiety, emotions and stresses that come with being diagnosed with and living with RA or JIA and its treatment.

Methods: Following a focus group held in Central London in early 2018 with a dozen NRAS members, NRAS and City University designed a survey to look at a range of aspects relating to emotional health and wellbeing, including validated questionnaires to compare data to existing research. The survey was open between May and July 2018, with participants recruited via NRAS newsletters, social media platforms, the NRAS HealthUnlocked forum and via healthcare professionals at rheumatology units. A total of 1,999 people participated in the survey and a final sample of 1,650 was used for analysis.

Results: The survey found that people with RA and adult JIA were less satisfied with their life, believed the things in their life were less worthwhile, and were less happy. The proportion of people who scored poorly on life satisfaction and life worth was over 7 times greater in those with RA and adult JIA than the national average. Despite this, the survey found that 2 in 5 people had never been asked by a health professional about their emotional and psychological well-being, and 1 in 3 people who had requested or been offered support had never received it. Positive experiences that respondents shared of psychological support, such as GPs and rheumatologists being very sup portive, the importance of family, and services offered by NRAS demonstrate the benefits of good and appropriate support being available. Negative experiences, such as lack of health professional understanding about mental health, lack of understanding of RA by counsellors, and lack of personalised care demonstrate the future work that must be done to help adequately support people with RA and adult JIA.

Conclusion: The survey has demonstrated the need to provide more effective self-management techniques of emotional as well as physical well-being, ultimately leading to overall improved health outcomes. In line with NICE guidelines, other additional support is needed, such as the availability of cognitive behavioural therapy and the implementation of mental health and well-being assessments at annual review. Further research is needed into specific areas, such as health inequalities and why people with severe mental health issues experience poorer disease activity, understanding why adults with JIA have poorer life quality than people with RA, and understanding the impact of psychological interventions for people with adult JIA.

\section{REFERENCES}

[1] Emotional Health and Well-being Matters, McBain, H., Bezzant, M., Bosworth, A., 2018.

Disclosure of Interests: None declared DOI: 10.1136/annrheumdis-2019-eular.5557 